\title{
A Prototype Mobile Application for Searching Specialized Medical Facilities in a Chosen Vicinity
}

\author{
Supasit Kajkamhaeng*, Komwit Surachat, Komkrit Kangrat, Jitpakan Limsakun
}

The Innovative Information Technology for Health Science and Society Research Unit, Information and Communication Technology Programme, Faculty of Science, Prince of Songkla University, Hat Yai, Songkhla, Thailand.

* Corresponding author. Email: supasit.kajkamhaeng@gmail.com.

Manuscript submitted February 18, 2015; accepted July 4, 2015.

doi: 10.17706/jsw.10.9.1119-1126

\begin{abstract}
When people experience specific illness or disorder, they usually prefer to be treated by medical specialists. Although there are possibly many health facilities in a defined area, especially private clinics, it could be difficult to distinguish the main medical specialty the facilities offer. Furthermore, patients generally want to know the operating hours of the health service in order to help them decide and select appropriate facilities at their most convenient time, and also further information for them to learn of the exact location, the route to the site and other useful details. In this study, we propose a design and prototype of mobile application for searching health facilities depending on their specialized services. The application provides users with a list of health facilities in an area which offer well-trained medical specialists to heal specific symptoms. Users can also search for facilities that operate on days and times at their requirement. In addition, the application will show details of those chosen facilities, such as name, location, phone number, etc. that can also be rearranged by distance from a defined position. Moreover, the application navigates users to the selected facility using Google Maps API Web Services.
\end{abstract}

Key words: Healthcare application, query-based medical information system, mobile application.

\section{Introduction}

Health is one of the most important things in life. Great health throughout a lifetime is thus a desire of everyone. However, nobody can definitely avoid illnesses, especially when they get older. Each individual generally tends to experience specific diseases, such as heart disease, bone disease, skin disease, diabetes, etc. For an effective and well-organized medical treatment, medicine study has been divided into branches according to characteristics and causes of the disease, for example, cardiology, orthopedics, dermatology, neurology, radiology, ophthalmology, otolaryngology, etc. [1] In addition, medical specialists for each division are trained to study, research, diagnose, and treat related specific diseases or disorders on patients. They also work at health facilities, such as hospitals, private clinics, etc., that service specialized therapy as illnesses occur.

The vast variety of specialties in medicine affects patients' choice in sorting out which health facilities and clinics surrounding them give what services to a specialized therapy corresponding to their needs. This issue is quite essential for patients because they commonly wish to be treated by adroitmedical specialists and with specialized medical equipment. Moreover, illness can occur anytime and anywhere, such as at 
night time, on weekend, while traveling, while in an unfamiliar area, or in a combined situation of these, that makes it more problematic to find the location of the required health facility that operates at that specific period of time.

Nowadays, there are healthcare applications for mobile devices used by medical personnel and patients to increase significantly the efficiency and convenience in medicine [2]-[4]. One of the approaches to solve the earlier mentioned problems is to apply an information technology (IT) on advancement of mobile devices, such as smartphone, tablet, etc., in order to build an information system to collect and manipulate health facilities' information. In addition, users can easily make information query on medical facilities based on their conditions via mobile application anyplace and any time.

In this paper, we propose a design and prototype of mobile application for searching health facilities depending on specialized medicine, coined "sMedSearch" (Specialized Medicine Search). The application is developed using HTML5 [5] that can generate cross-platform mobile application for iOS, Android, and Windows Phone. It provides users with a list of health facilities which offer well-trained medical specialists to treat specific patients' symptom. Users can also search for facilities which operate on specific day and time at their requirement. Furthermore, the application search results can be rearranged by distance from a user's defined position and can also navigate users to any selected facility using Google Maps API Web Services [6].

The paper is organized as follows: our system design and implementation in Section 2; our prototype of the application in Section 3; and conclusions and future work in Section 4.

\section{Design and Implementation}

We initially describe the system model shown in Fig. 1. The system has an application \& database server which provides two main functions to client and administrator. Firstly, the server is used to store information of health facilities, which are inserted and manipulated by an administrator via a web user interface, inclusive of name of health facility, type of health facility, list of physician, type of serviced specialized medicine, location (for example, street, district, province, latitude, andlongitude), office hours, telephone number, etc. Secondly, the server provides a search function for supporting queries under the conditions specified by a client via the sMedSearch application on mobile devices. In addition, client can define the center and the radius of a search in two ways. The first one is to use the client's current position obtained from GPS (Global Positioning System) [7], and another is to define any required position via Google Maps API Web Services. The application can also navigate the client to the selected health facility by using Google Maps API Web Services.

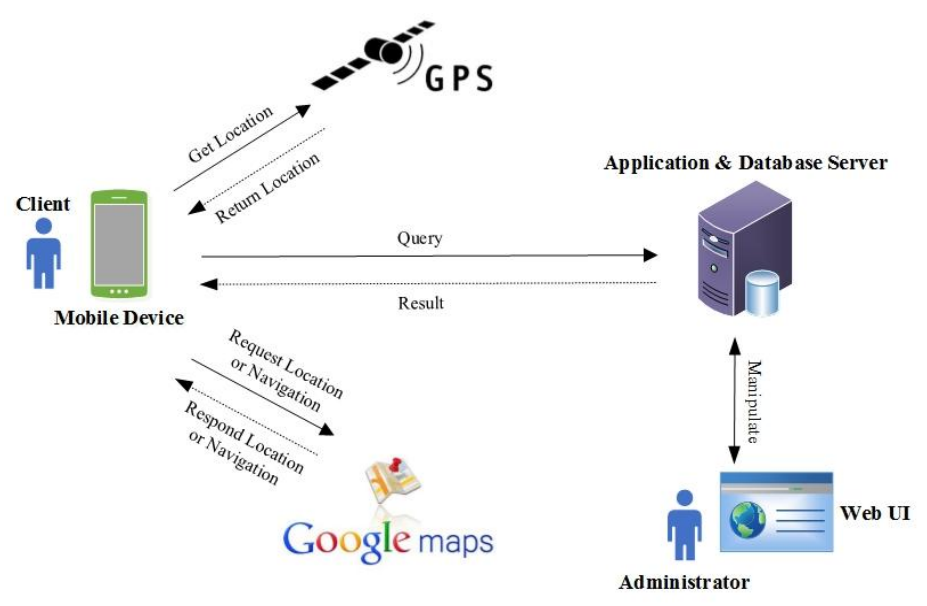

Fig. 1. System model. 
Next, we describe in more details about the procedure of searching health facilities operating on the system. Fig. 2 shows an overview of interaction between components on the system for searching health facilities. For the search operation, client must define two parts of input data to the sMedSearch application, thus:

1) Area - User has to firstly specify the center and the radius of the search space. The center can be identified alternatively from either the client's current position gotten from GPS (default) or other location defined through Google Maps API Web Services. Either way, the application recognizes the geolocation (the latitude and longitude coordinates of a particular location) and the name of the province of the defined center, which are returned from the GPS or Google Maps API Web Services (with Google Geocoding API [8]). These information are used later to consider whether each of the health facilities is located at the defined province and is not farther than the given radius calculated from the distance between the client's defined geolocation and the geolocation of the health facility.

2) Conditions - User subsequently defines conditions of searching about health facilities including medical specialty and office hours, i.e. days and time periods that the user is expecting to use the service.

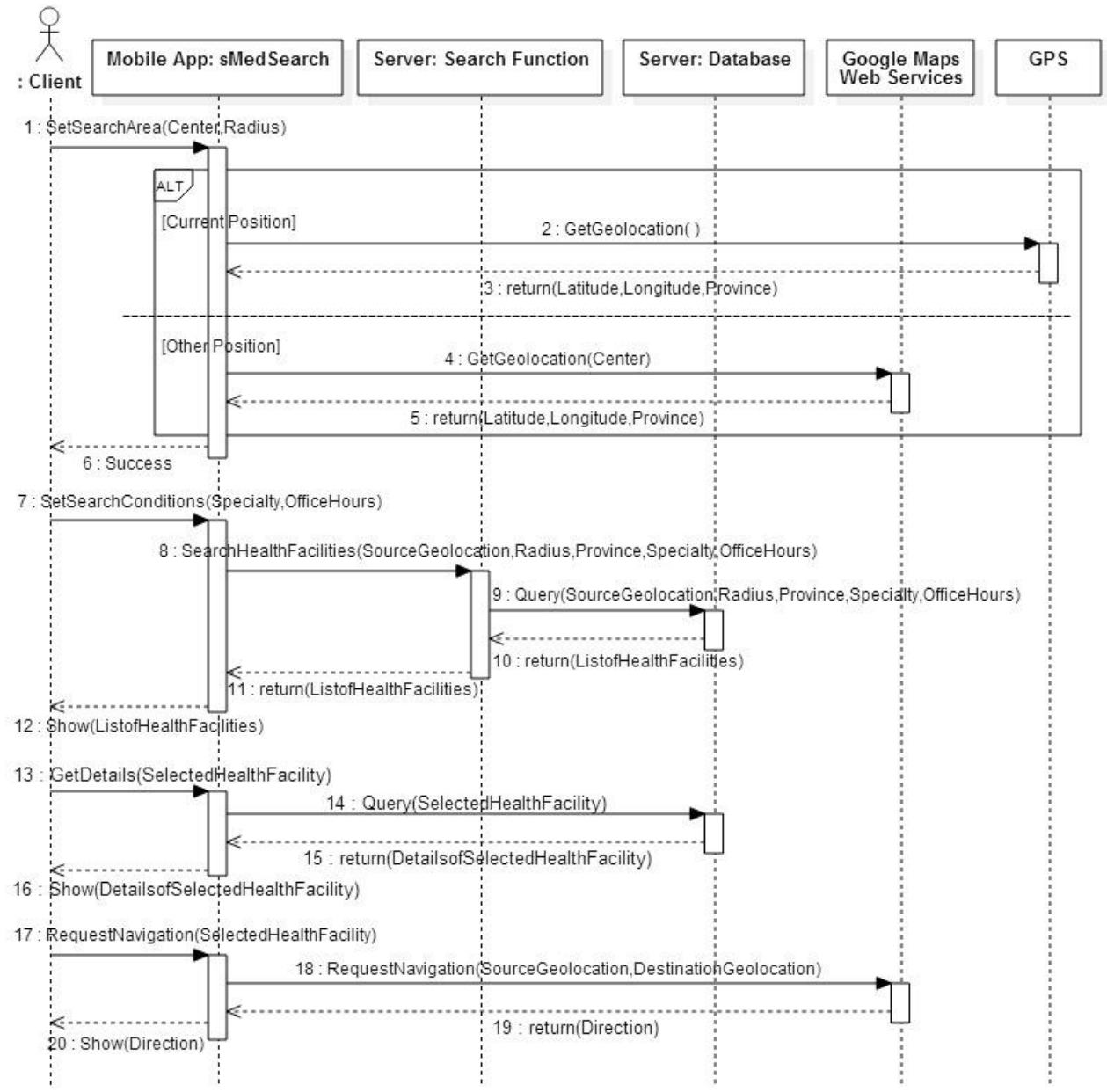

Fig. 2. Overview of interaction between components on the system for searching health facilities.

After the user enters the values in the input fields, the sMedSearch application sends parameters, including source-geolocation (the user-defined center of the search), radius, province, specialty, and office hours, to the search function on the application server. The procedure of the search function is detailed in Fig. 3. The search function searches the database that collects the information of health facilities to query 
and explore whether each of the health facilities corresponds to the user's requirements. In addition, the search is considered in four hierarchical steps by using respectively the user-defined area and conditions as criteria, thus:

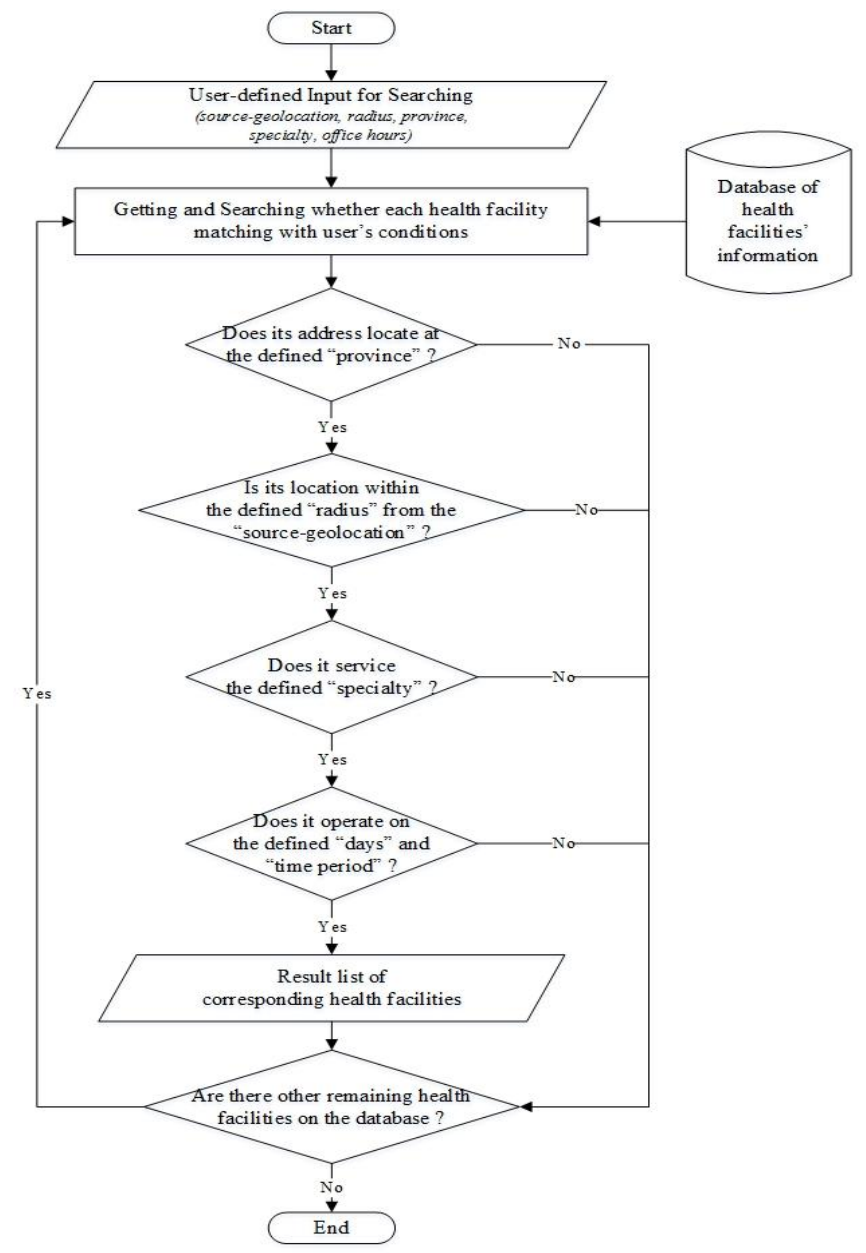

Fig. 3. Procedure of the search function.

1) The first step is to consider the "province" name in the health facility's address - the value is kept in a field on the database - as a criterion. If the field value of any health facility is the same as the name of the province in the area defined by the user, then that facility becomes one of the candidates which will be considered in the following steps. Actually, the main purpose of this first step is preliminary screening; as to whether each of the health facilities is located in the user-defined area, before thorough investigation in the second step concerning the distance from the user-defined center of the search to each of the selected locations is conducted. Thus, this first step is capable of considerably decrease the amount of execution time.

2) In the second step, the function examines all candidates (the result list of health facilities obtained from the first step) whether they are within the stipulated "radius" by calculating the distance between the source-geolocation and the geolocation of the health facility. If it is, then that health facility is inserted into the list of potential health facilities to be considered in subsequent steps of the procedure.

3) The third step is to seek any health facilities from the result list in the second step which serve the specialized medical service according to the user-defined "specialty". The result of process is then 
delivered to the fourth, and last, step.

"Office hours" of health facility is a criterion used in this last step. There are generally several service periods in each health facility, for example, Monday-Friday: 17:00-20:00 hrs. and Saturday-Sunday: 09:00-16:00 hrs. Thus, the function explores whether there are any service periods in the candidate list which operate in scope of "days" and "time period" defined by the user. For each of the candidates, each of its office hours is considered initially from the value of working days. If at least one day in the list of working days of the service period happens to be in the set of the defined days that the user expects to use the service, it will mean that this health facility operates on the user-defined days. The procedure subsequently examines the part of the time period of the service period. The approach in checking whether the service time period operates within the scope of the user-defined time period is detailed in Algorithm 1. The output of the approach is a final result list filtered from the list of health facilities that comply with the user's search conditions. This result is returned to the sMedSearch application to be presented to the client.

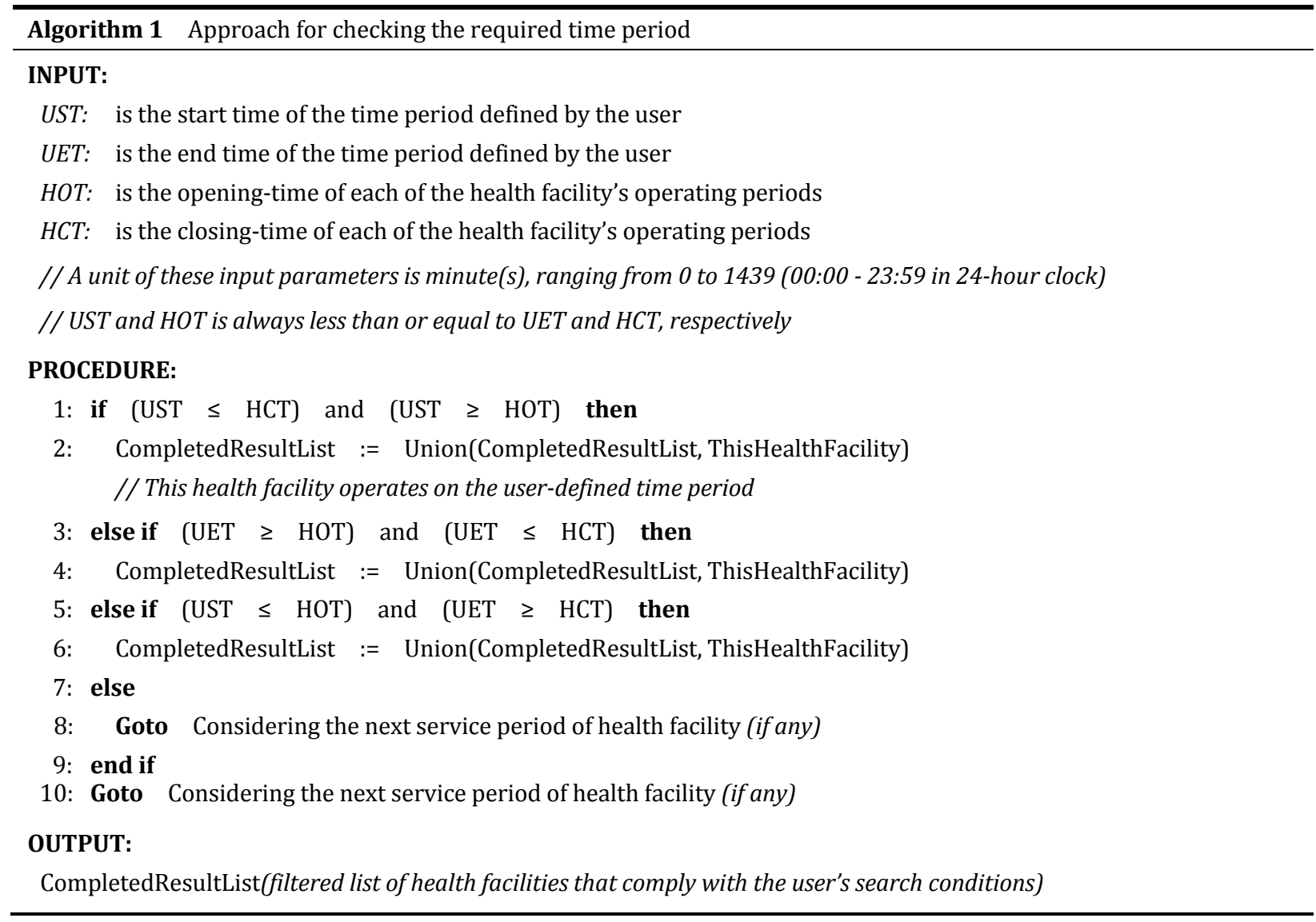

User could request further information of his/her interested health facility/facilities through the sMedSearch application that acquires details from the database server. The application can also navigate the user to the targeted health facility using the Google Maps API Web Services.

\section{Prototype of Application}

In this section, we illustrate the prototype of sMedSearch application. Fig. 4-6 show exampled screenshots of the prototype application. When user launches the application, it will initially display the screen of the search function, as shown in the Fig. 4(a) example. The screen lets the user define the area of search including the center position and its radius. The center is originally specified with the user's current location acquired from the GPS and is shown via the Google Maps API Web Services by default. In this 
example, the location of the user shown was at "Prince of Songkla University" (in Thai language: "มหาวิทยาลัยสงขลานครินทร์"). However, clients may change their current position by tapping on the "Identify location" button and typing in the preferred location such as "Bangkok" (in Thai language: "กรุงเทพมหานคร"), and the application will display the new location acquired from Google Maps API Web Services, as shown in the Fig. 4(b) example. User can also freely fine-tune the position by moving the marker on the map to the desired location, such as the "Victory Monument" (in Thai language: "อนุสาวรียัชัยสมรภูมี")as shown in the Fig. 4(c) example.

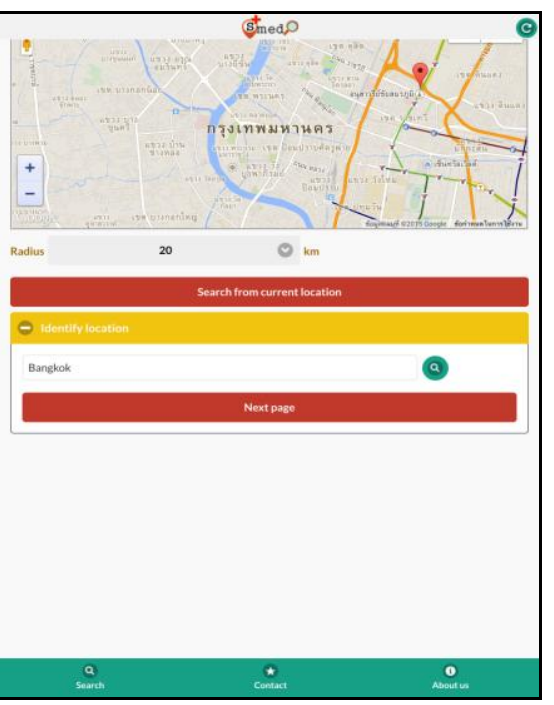

(a)

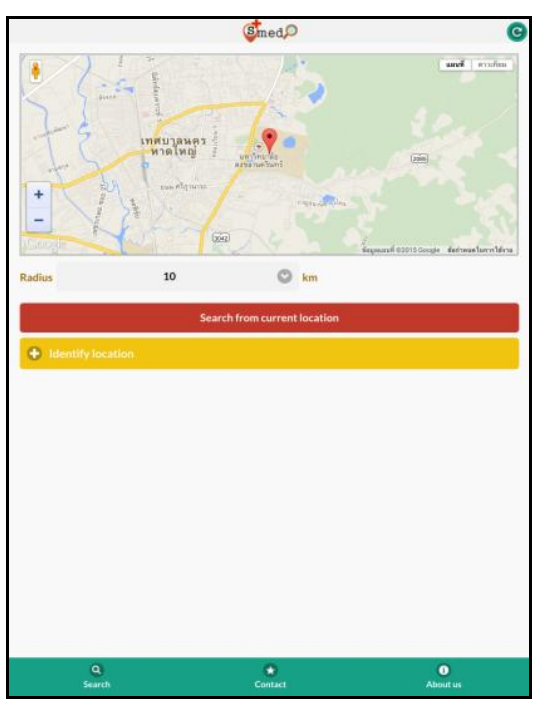

(b)

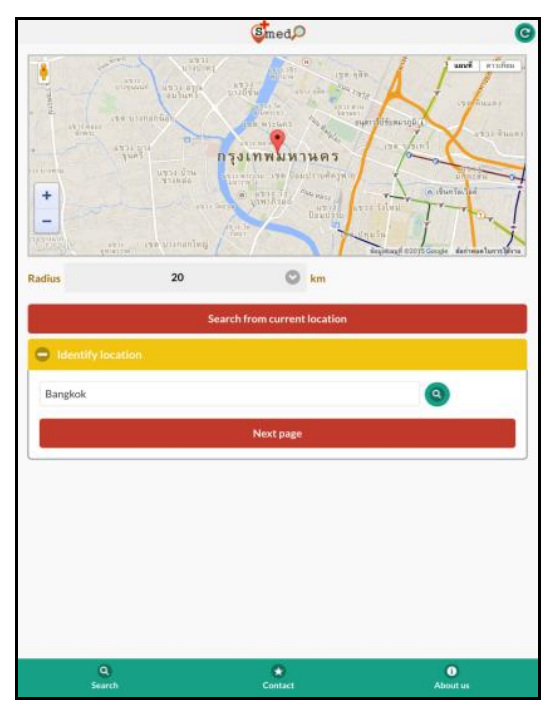

(c)

Fig. 4. Exampled screenshots of the prototype sMed search application for defining the area of search.

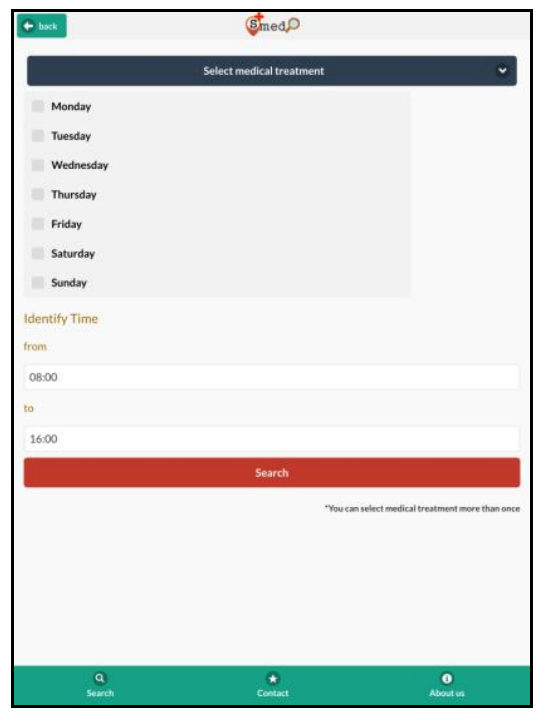

(a)

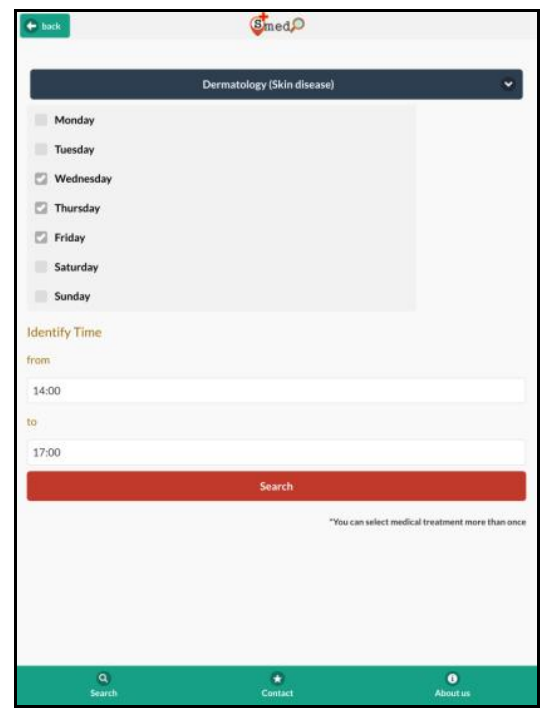

(b)

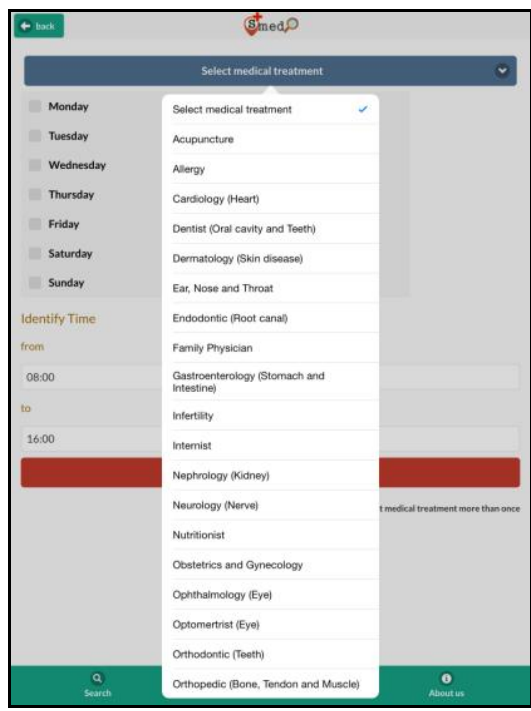

(c)

Fig. 5. Exampled screenshots of the prototype sMedSearch application for specifying the condition of search.

The next step is to specify the condition of the search including the type of medical specialty and the office hour that the user expects to use the service. Fig.5(a) shows the screen for determining these conditions. User can choose the required medical specialty from the prepared list as shown in Fig.5(b). An example screenshot which demonstrates the search condition is shown in Fig.5(c); in this case the client 
need to find any health facilities that specialize in "Dermatology (Skin disease)" that also operate on "Wednesday - Friday" during "14:00 - 17:00" hrs. The procedure of the search function detailed in Section 2 can now be launched. Fig. 6(a) illustrates an example result list of health facilities according to this user's requirements. The Application automatically sorts out the results from the nearest to the farthest distance from the user's defined position.

User may tap an interested health facility to view additional information of the place, as exampled in Fig. 6(b). Moreover, using icons on the side bar of the sorted result the application is capable of navigating the user to the targeted health facility using Google Maps API Web Services, as exampled in Fig. 6(c).

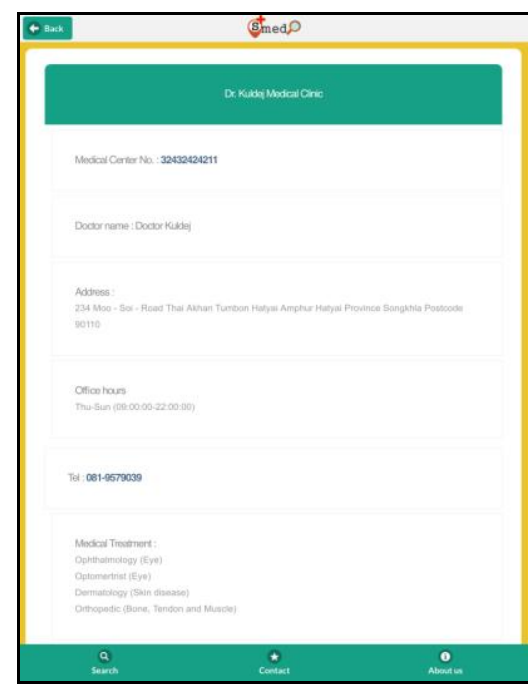

(a)

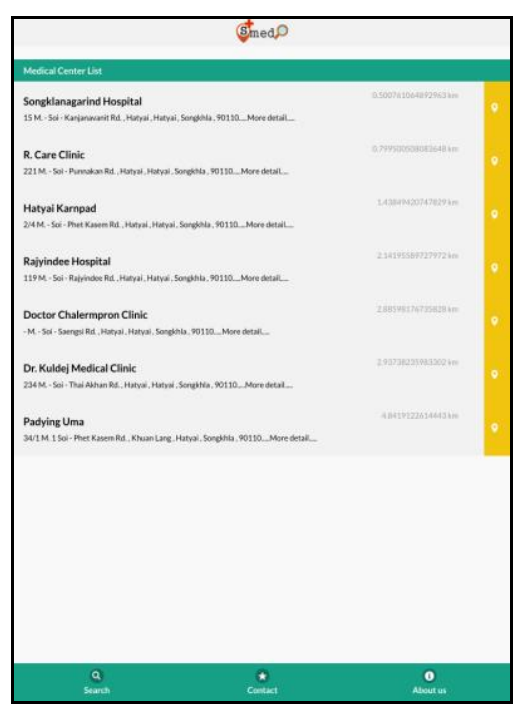

(b)

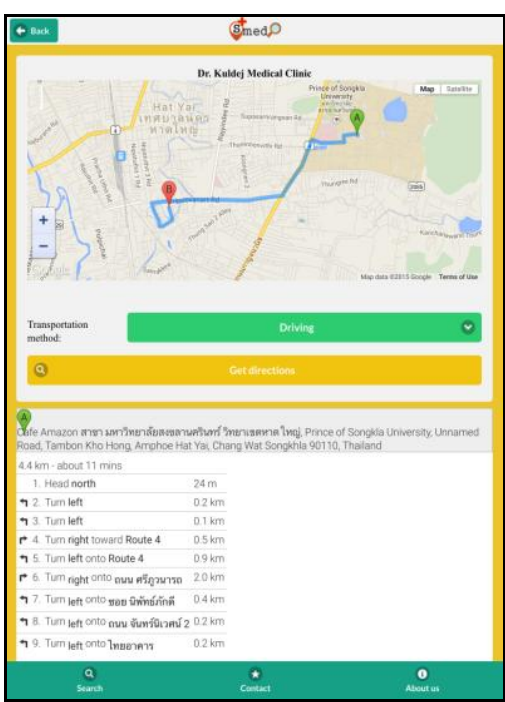

(c)

Fig. 6. Exampled screenshots of the prototype sMedSearch application for illustrating the result of search.

\section{Conclusion and Future Work}

Healthcare is one of the necessities in life. In a certain situation, searching of a health facility that can actually correspond to the patient's requirement is vital. There are many characteristics of health facilities that need be considered in a search, such as medical specialty, office hours, and location, etc. In this research, we propose a design and implementation of an application for searching health facilities using some of these factors to filter out heath facilities in order to assist a client to search for an establishment that matches his/her conditions as much as possible; an application can also navigate a client to the targeted health facility. In order to make this a most convenient application for a user to quickly search for the information anywhere and anytime, we have developed a sMedSearch application that can be launched on mobile devices such as a smartphone or a tablet.

Our work could be improved many ways in the future. More useful functions may be added for additional beneficial usage, for example, a favorite menu to store the preferred health facilities on a local storage of the mobile device, a speed dial from the facility results, etc. For the ever-growing amount of information, we will have to develop an efficient search algorithm on the database to minimize the execution time of a query.

\section{Acknowledgment}

This research is supported by the Information and Communication Technology Programme, Faculty of Science, Prince of Songkla University, Thailand. 


\section{References}

[1] European parliament and council. (2005). Retrieved March 25, 2015, from http://eur-lex.europa.eu/legal-content/EN/ALL/?uri=CELEX:32005L0036

[2] Mosa, A. S. M., Yoo, I., \& Sheets, L. (2012). A systematic review of healthcare applications for smartphones. BMC Medical Informatics and Decision Making, 12.

[3] Ozdalga, E., Ozdalga, A., \& Ahuja, N. (2012). The smartphone in medicine: a review of current and potential use among physicians and students. Journal of Medical Internet Research, 14(5).

[4] Prgomet, M., Georgiou, A., \& Westbrook, J. (2009). The impact of mobile handheld technology on hospital physicians' work practices and patient care: A systematic review. Journal of the American Medical Informatics Association, 16(6),792-801.

[5] Zibula, A., \& Majchrzak, T. A. (2013). Cross-platform development using HTML5, query mobile, and phone gap: Realizing a smart meter application. Web Information Systems and Technologies, Lecture Notes in Business Information Processing, 140, 16-33.

[6] Google developers website. Retrieved March 25, 2015, from https://developers.google.com/maps/documentation/webservices/

[7] Hofmann-Wellenhof, B., Lichtenegger, H., \& Collins, J. (1993). Global Positioning System: Theory and Practice. Springer-Verlag Vienna.

[8] Google Developers website. Retrieved March 25, 2015, from https://developers.google.com/maps/documentation/geocoding/

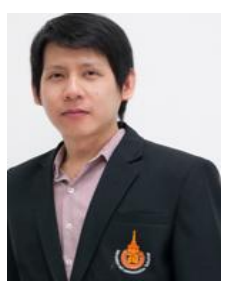

Supasit Kajkamhaeng was born in Songkhla, Thailand. He is currently a lecturer in the information and communication technology programme, Faculty of Science, Prince of Songkla University, Thailand. He received the master's degree in the Department of Computer Engineering, Faculty of Engineering, Kasetsart University, Thailand. His research interests include parallel/distributed computing and high performance computing.

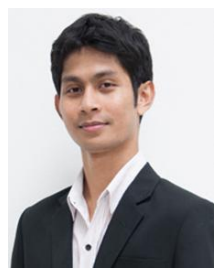

Komwit Surachat received the bachelor's degree in computer engineering from King Mongkut's University of Technology Thonburi in 2009, and received the master's degree in electrical and computer engineering at the Same Place in 2010. He is currently a lecturer in information and communication technology programme, Faculty of Science, Prince of Songkla University, Thailand. His research interests include digital image watermarking, digital image processing and pattern recognition.

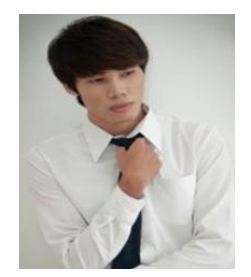

Komkrit Kangrat was an undergraduate student in the information and communication technology programme, Faculty of Science, Prince of Songkla University, Thailand.

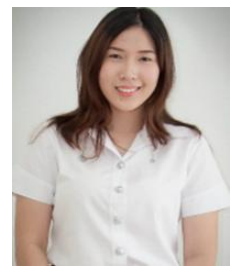

Jitpakan Limsakun was an undergraduate student in the information and communication technology programme, Faculty of Science, Prince of Songkla University, Thailand. 